\title{
Belief in Astrology: a social-psychological analysis
}

\author{
Martin Bauer ${ }^{1}$ and John Durant ${ }^{2}$
}

\begin{abstract}
Social scientists have suggested several different hypotheses to account for the prevalence of belief in astrology among certain sections of the public in modern times. It has been proposed: (1) that as an elaborate and systematic belief system, astrology is attractive to people with intermediate levels of scientific knowledge [the superficial knowledge hypothesis]; (2) that belief in astrology reflects a kind of 'metaphysical unrest' that is to be found amongst those with a religious orientation but little or no integration into the structures of organized religion, perhaps as a result of 'social disintegration' consequent upon the collapse of community or upon social mobility [the metaphysical unrest hypothesis]; and (3) that belief in astrology is prevalent amongst those with an 'authoritarian character' [authoritarian personality hypothesis].

The paper tests these hypotheses against the results of British survey data from 1988. The evidence appears to support variants of hypotheses (1) and (2), but not hypothesis (3). It is proposed that serious interest or involvement in astrology is not primarily the result of a lack of scientific knowledge or understanding; rather, it is a compensatory activity with considerable attractions to segments of the population whose social world is labile or transitional; belief in astrology may be an indicator of the disintegration of community and its concomitant uncertainties and anxieties. Paradoxical as it may appear, astrology may be part and parcel of late modernity.
\end{abstract}

\section{Introduction}

Across the industrialized world, astrology has attractions for large numbers of people. Horoscopes are read by millions; astrologers are personally

\footnotetext{
${ }^{1}$ London School of Economics, Department of Social Psychology

${ }^{2}$ Science Museum and Imperial College, London
} 
consulted by tens or hundreds of thousands; rumour has it that the London City is a booming place for astrological consultancy; even the wives of Presidents ${ }^{1}$, it appears, may consult with astrologers before advising their husbands on how to conduct affairs of state. In all these situations astrology seems to offer a degree of certainty where uncertainty prevails. To many scientists and science educators who are concerned about the public understanding of science, the enduring popularity of astrology is an affront. How can it be, they ask, that in the last decade of the 20th century so many people are still prepared to embrace pre-scientific and even frankly superstitious belief systems?

Faced with the task of accounting for the enduring popularity of astrology, it is tempting to invoke the phenomenon of 'anti-science' - that is, active resistance to the principles and practises of science. In this context, it may be significant that the first of a series of US-Soviet conferences on the social and political dimensions of science and technology, which was held at the Massachusetts Institute of Technology in May 1991, was devoted to 'Anti-Science Trends in the United States and the Soviet Union'. Significantly, the two parallel keynote addresses to this conference - by Gerald Holton, of Harvard University, and Sergei Kapitza, of the Institute for Physical Problems (Moscow) - pointed to the need for a critical understanding of the phenomenon of anti-science. According to Holton antiscience in the US is symptomatic of a long-standing struggle over the legitimacy of the authority of conventional science, ${ }^{2}$ while for Kapitza, antiscience in the east is part and parcel of the wider social and political transformation of the former Soviet Union. ${ }^{3}$

In a recent $\mathrm{BBC}$ radio programme prominent representatives of churches, science, and the arts discussed the apparent popularity of astrology and parasciences in Britain under the label 'pre-millennium tension' [PMT]. ${ }^{4}$ Ironically, on the issue of astrology and parasciences, the traditionally polarised positions of science and religion converged. It seems that present day astrology claims the territory which makes the Church and Science equally nervous. Albeit, the nervousness may have different sources.

In this paper, we investigate the phenomenon of popular belief in astrology in Britain in the late 20th century. Our evidence concerning the place of astrology in British culture is derived from the results of a 1988 national random sample survey designed to estimate levels of public interest in, understanding of and attitudes towards science and technology. In the course of this survey several questions were asked about astrology ${ }^{5}$. The results of these items enable us to explore three different sociological hypotheses which have been advanced to account for the prevalence of 
belief in astrology amongst certain sections of the public: first, that astrology is attractive to people with intermediate levels of scientific knowledge [superficial knowledge hypothesis]; second, that astrology is attractive to people who possess what has been termed 'metaphysical unrest' without integration into a Church; their unrest could therefore be considered freefloating [metaphysical unrest hypothesis]; and third, that belief in astrology is prevalent amongst people with authoritarian personality characteristics [authoritarian personality hypothesis].

Astrology must be considered the "grandmother" of modern science in at least two aspects: its concern with regularities in the universe, and its attempt to deal with these regularities numerically. Keith Thomas observed that 'at the beginning of the 16th century astrological doctrines were part of the educated man's picture of the universe and its workings'; London was a booming centre of astrological divinations for a mainly elite clientele of Court, nobility and Church until its decline in the mid-17th century. ${ }^{6}$ In one sense it is not surprising that in a country that prides itself on tradition and continuity we find residuals or even revivals of such activities in the late 20th century. In this paper we try to locate contemporary belief in astrology in order to understand its social and psychological functions; while temporarily abstaining from evaluations of the belief itself.

We begin by defining our measures of public belief in astrology, and then proceed to use these measures to explore the three hypotheses.

\section{Measuring Popular Belief in Astrology}

The British survey was conducted in the early summer of 1988 . The sample of 2009 respondents was designed to be representative of the adult population of Britain over the age of eighteen. The survey was conducted by means of face-to-face interviews lasting between forty minutes and one hour. The questionnaire covered a wide variety of topics in the general field of science and technology. In particular, it developed a multi-item scalar measure of scientific understanding. Further details of the survey methodology and the results on public understanding of science have been published elsewhere. ${ }^{7,8,9,10}$

So far as the present study is concerned, the following items from this national survey are of particular interest. First, respondents were asked 'Do you sometimes read a horoscope or a personal astrology report?'. Those 
who responded positively were then asked (a) how often they read a horoscope or personal astrology report [frequency] and (b) how seriously they took what these reports said [seriousness]. $73 \%$ of respondents claimed to read a horoscope or personal astrology report. $21 \%$ said that they would read it 'often', 23\% 'fairly often', 29\% 'not often', and 27\% did not read it 'at all'. Hence, $44 \%$ claimed to do so often or fairly often. However, a rather smaller number of respondents $(6 \%)$ claimed to take what horoscopes or personal astrology reports said either 'seriously' or 'fairly seriously'. $67 \%$ took it not very seriously, and $27 \%$ took it not at all seriously. This result points immediately to the problematic status of astrology in the minds of many of those who take at least some personal interest in it.

Figure 1: the combined percentages of respondents for two questions: 'how frequently do you read astrology columns?' and 'how seriously do you take it?'

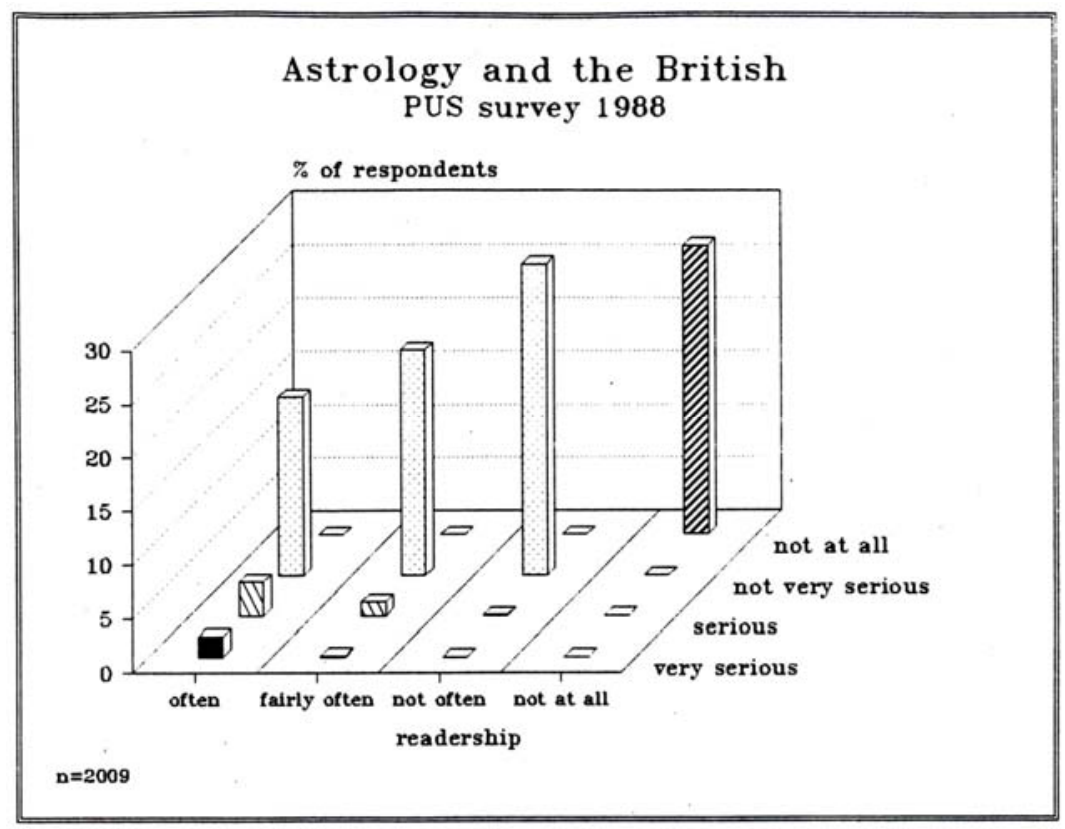

Culture and Cosmos 
In order to accommodate these results in a useful way, we have combined them into a single scalar measure. Figure 1 brings together the results on readership and seriousness, which we combined into a 5 point-scale of belief in astrology. The scale is derived from the readership and seriousness results in the following way: those who reported that they read horoscopes often or fairly often and that they took them seriously or fairly seriously are ranked 5 (serious believers 5\%); those who reported that they read horoscopes often and that they took them not very seriously are ranked 4 (non-serious believers, 18\%); those who reported that they read horoscopes fairly often and that they took them not very seriously are ranked 3 (non-serious believers, $21 \%$ ); those who reported that they read horoscopes not very often and that they took them not very seriously are ranked 2 (non-serious believers, 29\%); and those who reported that they did not read horoscopes at all are ranked 1 (non-believers, $27 \%$ ). ${ }^{11}$ With around $5 \%$ of the population or 2.5-3 million, the constituency of serious believers in astrology is a small minority compared to the constituency adhering to basic religious creeds such as 'God', a 'life after death' or 'miracles', which includes half or more of the British population. ${ }^{12}$ For much of the following analysis the 5-point scale is reduced by pooling $1+2,3$, and $4+5$ into a 3 -point scale.

Another item in the survey invited respondents to estimate the scientific status of astrology (which was defined as 'the study of horoscopes') on a 5 point-scale, from 'not at all scientific' to 'very scientific'. 32\% of respondents stated that astrology was not at all scientific (scale point 1), while $13 \%$ stated that it was very scientific (scale point 5 ); $18 \%$ said it was in between (scale point 3); a further $17 \%$ tended towards 'not scientific' (scale point 2), and 14\% tended towards 'scientific' (scale point 4); $5 \%$ did not know.

Our survey incorporated two standard measures concerning religious belief and religious integration. Religious belief was constructed as a scalar measure on the basis of responses to the following agree/disagree items: 'spiritual values taught by religion are important'; 'there is no such thing as a God'; 'people should rely more on the power of prayer'; and 'Adam and Eve never really existed' ${ }^{13}$ Religious affiliation was constructed as a scalar measure on the basis on the following items: 'Do you regard yourself as belonging to any particular religion?'; and (if yes), 'Apart from such special occasions as weddings, funerals and baptisms, how often nowadays do you attend services or meetings connected with your religion?'. ${ }^{14}$

Finally, the survey comprised two standard scales on 'authoritarianismegalitarianism' and 'social efficacy'. Authoritarianism is indicated by consistently agreeing with statements such as 'censorship of film and 
magazines is necessary to uphold morality' or 'school should always teach children to obey authority'. Social efficacy is indicated by disagreeing with statements such as 'I feel it's very difficult to have any real influence on what other people do or think' or agreeing with 'people like me can influence the government by taking an active part in politics'.

\section{Exploring the Basis of Popular Belief in Astrology}

Equipped with the measures that have been described above, we can begin to explore the basis of popular belief in astrology. We shall do this by considering in turn three different hypotheses that have been advanced to account for this phenomenon.

\section{i. Superficial Knowledge}

It has been claimed that belief in astrology is the product of a relatively slight or superficial acquaintance with the stock of modern scientific knowledge. On this view, people with what might be termed an intermediate level of scientific understanding may be attracted by astrology because it possesses many of the 'trappings' of orthodox science (systematic structure, predictive power, numeracy etc.); but they may be insufficiently well equipped to see that these things really are the 'trappings' rather than the substance of genuine science. Thus, in his classic paper of 1957 on the Los Angeles Times Astrology Column as an example of 'secondary superstition', Theodor Adorno wrote as follows:

While the naive persons who take more or less for granted what happens hardly ask the questions astrology pretends to answer and while really educated and intellectually fully developed persons would look through the fallacy of astrology, it is an ideal stimulus for those who have started to reflect, who are dissatisfied with the veneer of mere existence and who are looking for a 'key', but who are at the same time incapable of the sustained intellectual effort required by theoretical insight and also lack the critical training without which it would be utterly futile to attempt to understand what is happening. ${ }^{15}$

We may pass over what seem by today's standards the somewhat elitist and patronising tones of Adorno's analysis. What concerns us here is whether the basic prediction - that astrology is attractive to people with intermediate 
levels of scientific understanding - is fulfilled. If that were the case, we would expect belief in astrology to be positively correlated with knowledge of science up to a certain level of scientific knowledge, beyond which this correlation becomes negative. In other words, we would expect a non-linear inverted U-shape relationship shown between scientific knowledge and the status of astrology.

This issue may be addressed by comparing the results of our question on the scientific status of astrology with the results of our multi-item scalar measure of scientific understanding. Figure 2 shows these results, compared with those for a similar item on the scientific status of physics. While there is a linear relationship between scientific understanding and the perceived scientific status of physics, there is a curvilinear relationship between scientific understanding and the perceived scientific status of astrology. In other words, our data do indeed bear out Adorno's hypothesis.

It should be noted that Figure 2 gives the proportions of respondents who ranked astrology and physics as 'very scientific'. We can learn a little more by comparing these results with those for other available options concerning the scientific status of astrology. Figure 3 shows the results for three groups of respondents: those who stated that astrology is not scientific (responses 1 +2 ); those who stated that astrology is neither scientific nor unscientific, or who said they didn't know (neither + don't know); and those who stated that astrology is scientific (responses $4+5$ ). Those with low levels of understanding have a strong tendency to avoid a definite judgement about astrology; while those with high levels of understanding have a strong tendency to state that astrology is unscientific. Amongst those with intermediate levels of understanding, there is less obvious consensus: some think astrology is scientific, some think it is not, and some don't know.

So much for the perceived scientific status of astrology. What, we may ask, about belief? Figure 4 compares belief in astrology with scientific understanding measured by a 28 -item knowledge quiz. ${ }^{16}$ As we might expect overall there is a negative correlation between scientific understanding and belief in astrology $(r=-.21)$. However, on closer inspection it emerges that this negative correlation applies only to the 
Figure 2: the scientific status attributed to physics and astrology in relation to the level of understanding of science; percentage of respondents saying 'scientific' or 'very scientific' combined.

\section{Scientific status of physics and astrology}

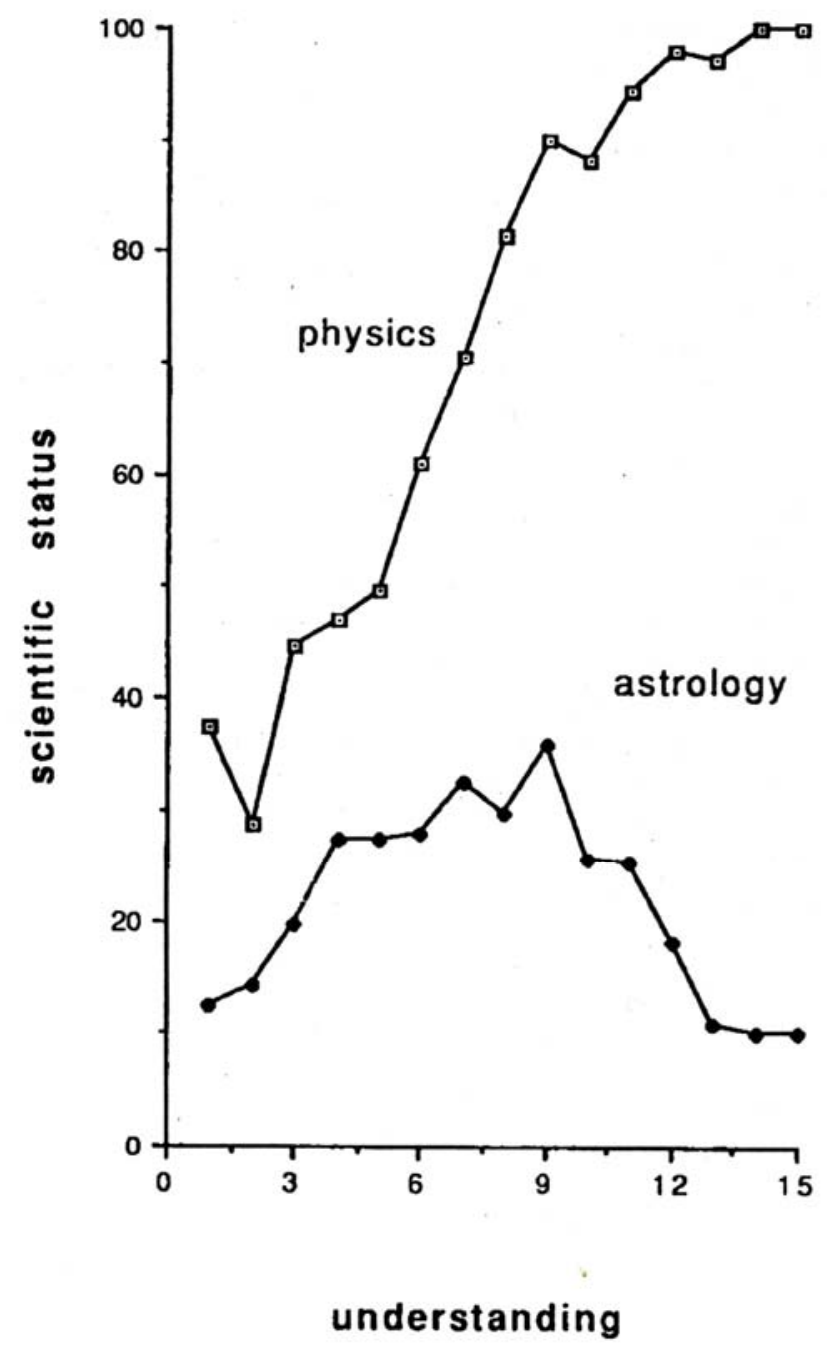

Culture and Cosmos 
Figure 3 shows the percentage of respondents saying that 'astrology is not scientific', 'don't know' or 'astrology is scientific' in relation to levels of understanding of science.

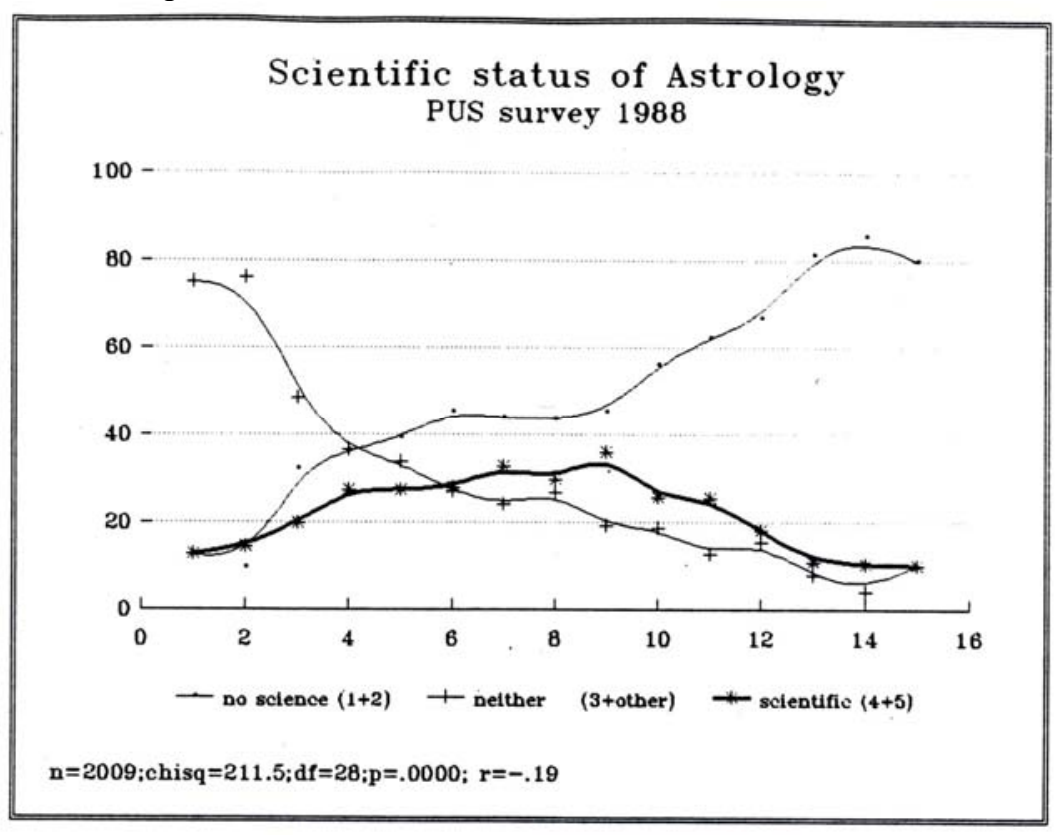

upper half of the understanding scale. We may wish to ignore the sudden jump of belief in astrology at the very top of the knowledge scale, which is based on a too few observations to be significant. However, within the $50 \%$ of the general public whose relative scientific understanding is below average, there is no correlation at all between levels of understanding and belief in astrology. This is a pointer to a potential problem with measures of scientific literacy that incorporate questions on the scientific status of astrology. ${ }^{17}$ Empirically, astrology and science are not mutually incompatible at least at lower levels of scientific enculturation. To use astrology as a threshold measure for 'scientific literacy' may be justifiable on normative grounds, but it ignors the social phenomenon of compatibility or incompatibility between these two forms of knowledge, which is itself a significant cultural variable. We expect the correlation to differ across cultural contexts. ${ }^{18}$ 
Figure 4 shows the average intensity of belief in astrology in relation to the level of scientific understanding.

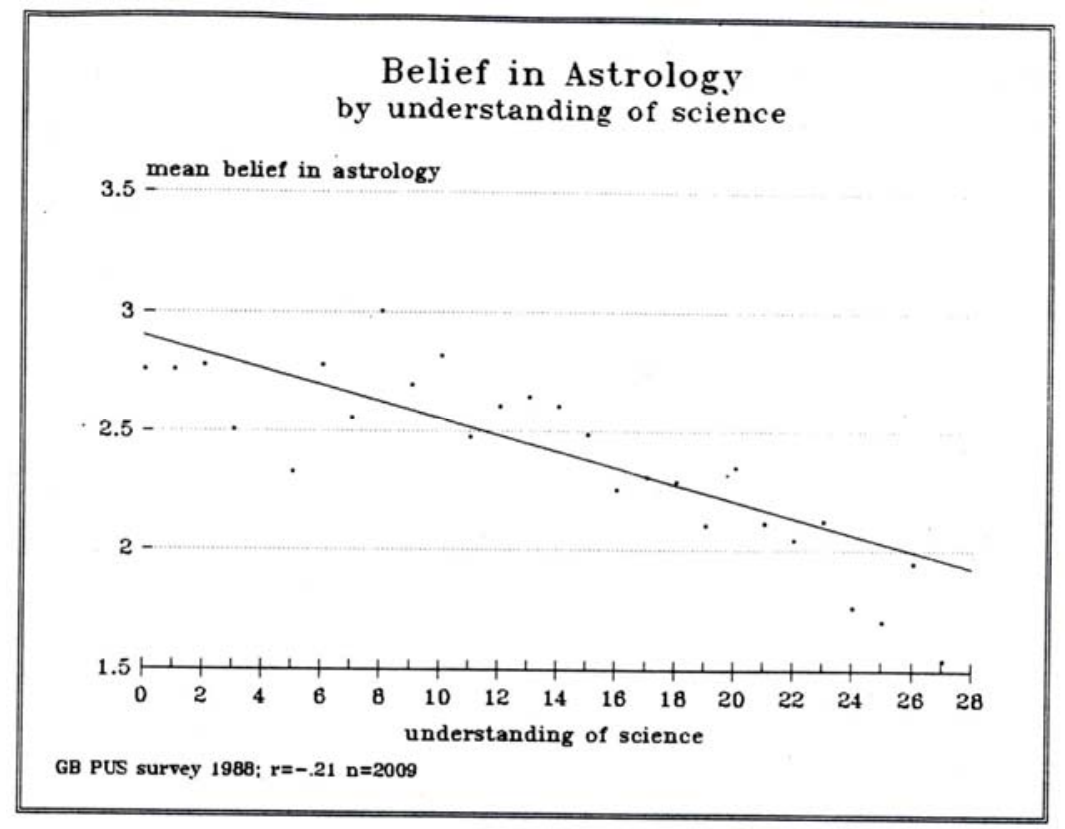

\section{ii. 'Metaphysical Unrest'}

It has been claimed that astrology has particular attractions for people who are alive to religion but who are poorly integrated into the institutional structures of a religious community. In this category are, for example, those who have been brought up in a particular religion and retain a religious outlook on life, but who for one reason or another (including social mobility or the collapse of community) have ceased to be closely tied to the particular church in which they were raised. Thus, Maitre and Boy \& Michelat have observed in France of the 1960s and 1980s and Schmidtchen in Germany of the 1950s that astrology tends to be less popular amongst those who are closely integrated into the institutions of organized religion. The French characterize astrology as a petit-bourgeois phenomenon of social uncertainty, social isolation and individualisation. ${ }^{19}$ According to Valadier, this result is consistent with the hypothesis that astrology feeds 
upon a free-floating 'metaphysical unrest', or a desire to recover a sense of the sacred and a sense of unity on the part of people whose life world no longer provides for these experiences; Pollack sees it as one among many forms of religiosity-outside-the-church in the context of the collapse of old certainties in Eastern Germany. ${ }^{20}$ Based on these previous observations, we would expect to find serious inclinations towards astrology most prevalent among religious believers with little or no religious integration.

We may put this hypothesis to the test in the context of our British data. Our data show that there is a very slight tendency for belief in astrology to be greater amongst those with higher levels of religious belief $(r=0.10)$. However, inclination towards astrology is highest amongst those with intermediate levels of integration into the institutions of organized religion. Putting these results together, Figure 5 shows average belief in astrology in relation to both religious belief $(1=$ low; $3=$ high $)$ and religious integration $(1=$ low; 3 = high $)$.

Figure 5: the average intensity of belief in astrology in relation to religious belief and religious integration

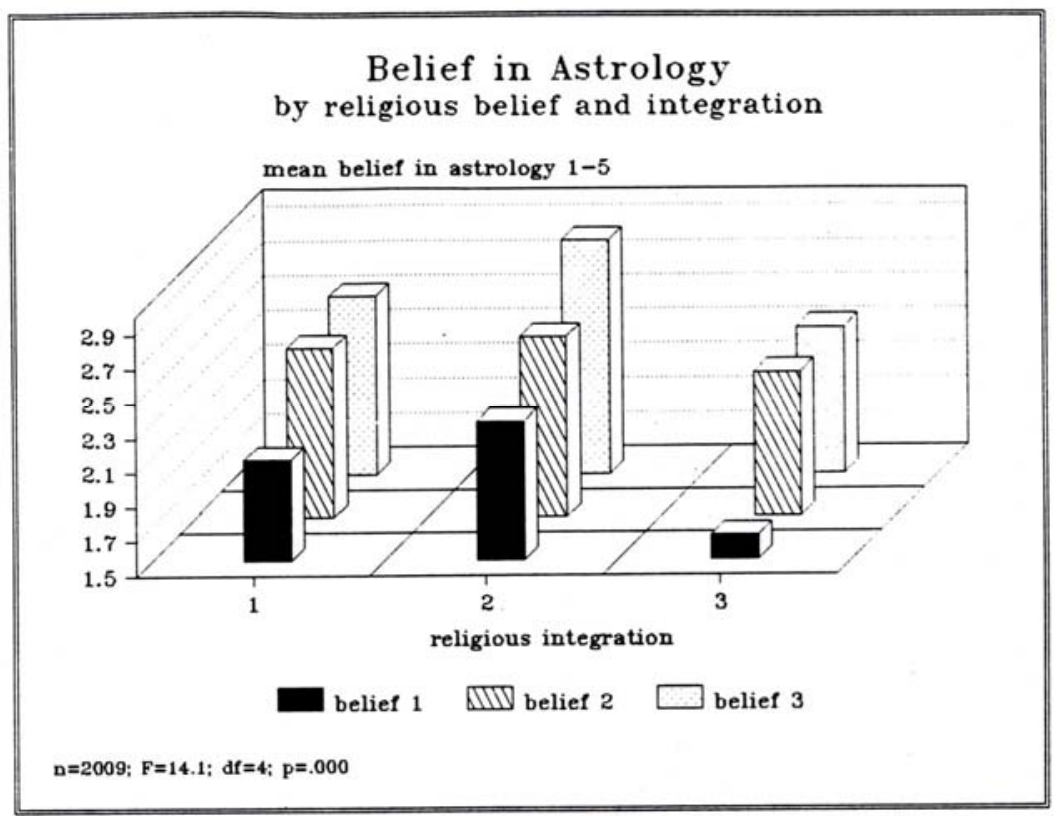

Culture and Cosmos 
We see that belief in astrology is highest amongst those who combine strong religious belief and intermediate or low religious integration. The fact that an intermediary level of integration is associated with highest level of belief in astrology is perhaps unexpected. On the other hand, it may be that having one foot in the Church and the other outside it may be the very situation of social uncertainty which Valadier takes as diagnostic for present-day belief in astrology. To this extent, therefore, we are able to confirm Valadier's hypothesis and Schmidtchen, Maitre and Boy \& Michelat's results suggesting that astrology has particular attractions for those who may be experiencing free-floating metaphysical unrest. Needless to say, our data do not permit us to explore the sources of such unrest in the lives of our respondents. This is an area where qualitative and biographical research may be more revealing.

\section{iii. The Authoritarian Personality}

The third and last hypothesis that we shall consider takes us back to the work of Theodor W Adorno. In the course of his analysis of astrology, Adorno noted that in general terms the astrological ideology resembles, in all its major characteristics, the mentality of the 'high scorers' of The Authoritarian Personality'. In addition to what he believed to be the narcissism, selfabsorption, naive empiricism and fatalism of astrology, Adorno pointed to its tendency to attribute everything negative in life to external, mostly physical circumstances. In these and other ways, he suggested, astrology had affinities with the authoritarian personality. ${ }^{21}$

Once again, our data may be used to test this hypothesis since the survey contained a standard battery of psychological items designed to provide measures of authoritarianism-egalitarianism and 'social efficacy', defined as personal sense of control over the social world. The data shows that in our study there is no significant tendency for belief in astrology to be greater amongst those who score higher on the authoritarianism scale. We find, however, that belief in astrology is stronger amongst those who score low on social efficacy $(\mathrm{r}=-.21)$. Astrology, it would seem, is indeed particularly attractive to persons with certain characteristics, namely those who have little sense of control over their lives. Thus, Adorno's hypothesis is not supported by our data, while the fatalism element was confirmed. Given that this famous authoritarian personality syndrome is more complex than our crude measure suggests, we suggest that further work is needed on this subject.

Culture and Cosmos 


\section{Characterizing the Believers in Astrology}

According to our results, the field in which the believers in astrology are generally to be found is one in which people possess intermediate levels of scientific understanding, high levels of religiosity, and low levels of religious integration. But what sorts of people are actually to be found within this field? In addition to what has already been said about personality, our data suggest that women are more likely to believe in astrology than men. Among the believers in astrology [scale 4+5] 77\% are women; among the declared sceptics $73 \%$ are men [scale 1+2]. With the exception of clerks (a high proportion of whom are, of course, women) self-employed, skilled and semi-skilled workers are in that order more likely to believe in astrology than people in professional and managerial occupations. It is interesting to note here that according to Boy \& Michelat, different social strata are associated with different sorts of 'para-interests': in France astrology is the pursuit of the less educated, while para-science is the pursuit of the highly educated. Our data do not allow us to compare this result with the situation in Britain.

These simple correlations are difficult to interpret because of the notorious problem of confounding variables. In other words, it may be that we find a correlation between belief in astrology and social class only because both in turn are related to some third factor (such as education, or social efficacy). To reduce the ambiguity of our results, we have subjected our data on belief in astrology to a form of statistical analysis (Logit modelling) which is designed to analyse differences between two unequally distributed groups. ${ }^{22}$ In this case, we wish to analyse the contributions to differences in astrological belief of each of a series of independent variables. Each independent variable is assessed individually, whilst possible effects from all other variables are controlled. This analysis ranks independent variables in order of importance, and it excludes variables which are found to make no statistically significant contributions.

We used a Logit model in which differences between sub-sets of the sample with respect to belief in astrology were analysed with the following independent variables: interest in science; understanding of science; religious belief; religious integration; authoritarianism; social efficacy; age; gender; marital status; social class; educational level; and nature of work (i.e. full/part-time). Comparing the extreme groups of serious astrology believers (ranked 5) with non-believers (ranked $1+2$ ) in this way, we obtain the following results. The variables which are relevant for the model 
are in order of importance: (1) gender, (2) religious belief, (3) living alone or in partnership, (4) age, (5) religious integration, and (6) the attributed scientific status of astrology. All other variables are irrelevant in explaining the difference between serious believers and sceptics. Note that the religious variables remain important, while personality and scientific understanding fall out of the equation. This indicates that the 'metaphysical unrest' hypothesis may be the strongest of the three hypotheses.

Comparing the category of playful, non-serious believers in astrology (ranked 4) with the sceptics (ranked $1+2$ ), we obtain slightly different results. Again in order of importance the following variables are relevant: (1) gender; (2) marital status; (3) social efficacy; (4) educational level; and (5) attributed scientific status of astrology. In distinguishing between the playful and curious approach to astrology and the sceptics we lose the religious variable from the equation and gain education and efficacy.

At least as significant as the list of items that appear in these analyses is the list of items that do not. From these results, it would appear that interest in science and scientific understanding are not significant contributors to variations in belief in astrology. This, in turn, casts serious doubt on the advisability of employing measures of belief in astrology as constituent items in larger constructs concerned with scientific understanding or scientific literacy.

On the basis of these results, we can risk a caricature of believers in astrology. Serious believers in astrology tend to be: female rather than male; single rather than living with partners; younger rather than older; and religiously motivated rather than indifferent; and inclined to attribute scientific status to astrology. The non-serious and playful astrology consumer also tends to be female and to live alone, to be less educated, less in control of their affairs, and to consider astrology to be more scientific than the sceptics allow.

\section{Conclusion}

We began by citing recent concerns at the rise of astrology as an anti-science phenomenon, East and West. Kapitza suggests that in part the rise of antiscience in the (former) Soviet Union may be explicable in terms of the ideological collapse of the Soviet empire. Such a collapse may be expected to have left an intellectual and spiritual vacuum, and this in turn will have helped to bring about a certain amount of social disintegration. Similarly, Holton proposes that the anti-science phenomenon in the United States

Culture and Cosmos 
should be understood as part of a deeper opposition both to the authority of science and to a certain conception of modernity. Both of these analyses invite us to consider popular belief in astrology as a great deal more than the passive result of mere ignorance.

In general, we suggest that there are three different ways of approaching the problem of popular belief in astrology. First, it may be regarded positivistically, as an anachronistic survival of a pre-scientific world-view. In this context, popular belief in astrology is seen as an atavistic phenomenon. Second, it may be regarded anthropologically, as an alternative world-view deserving of attention and respect in its own right. In this context, we are required to make no value-judgements about the respective merits of non-scientific and scientific positions. Third, it may be regarded sociologically, as one among a number of potential compensatory activity that may be attractive to individuals who are struggling to come to terms with the uncertainties of life in late modernity.

In this paper, we have inclined towards the last of these approaches. Belief in astrology is rather a matter of the moral fabric of modern society than of scientific literacy. It seems that in Britain, as in Germany or France, belief in astrology is prevalent among particular social groups; groups which, as we have indicated, may be experiencing difficulty in accommodating their religious feelings to life in an uncertain post-industrial culture. Paradoxical as it may seem, therefore, we conclude that popular belief in astrology may be part and parcel of late modernity itself.

\section{References}

1. An earlier version of this paper was given to the Annual Meeting of the American Association for the Advancement of Science in Chicago, 9 February 1992; at the time it was common currency that Nancy Reagan, the wife of former President Reagan, was consulting with astrologers on matters of US state affairs.

3. Kapitza S (1991) 'Anti-science trends in the USSR', Scientific American, 265, 2, August, $18-24$.

4. 'Moral Maze', 14 November 1996, BBC4, 9.00-10.00; moderated by Melvin Bragg. This term is a slightly sexist pun on the medically controversial 'pre-menstrual tension'.

5. Acknowledgement: The 1988 British national survey of public understanding of science is a joint Science Museum/University of Oxford and Community Planning Research (SCPR) project funded by the Economic and Social Research Council, grant numbers: A 09250013 and A 418254007 . 
70 Belief in Astrology: a social-psychological analysis

6. Thomas K (1971) Religion and the Decline of Magic. Studies in popular Beliefs in the 16th and 17th Century, London, Penguin, 337ff.

7. Durant J R, Evans G A and Thomas G P (1989) 'The public understanding of science', Nature, 340, 11-14.

8. Evans G A \& J R Durant (1989) Understanding of Science in Britain and the USA, British Social Attitudes: Special international report, edited by R Jowell et al., Aldershot, Gower, 105-119.

9. Durant J R , G A Evans and Thomas G P (1992) 'Public Understanding of science in Britain: the role of medicine in the popular representation of science', Public Understanding of Science, 1, 2, 161-183.

10. Evans G and J Durant (1995) 'The relationship between knowledge and attitudes in the public understanding of science in Britain', Public Understanding of Science, 4, 1, 57-74.

11. To measure the internal consistency of the 'belief in astrology' scale we use Cronbach Alpha's Reliability Coefficient: 0.92. Alpha is a measure for the covariance among all the items in the scale; Cronbach L J (1951) Coefficient alpha and the internal consistency of tests, Psychmetrica, 16, 297-334.

12. Greeley A (1992) 'Religion in Britain', Ireland and the USA, in: R Jowell, L Brook, B Prior, B Taylor (eds) British Social Attitudes, the 9th report, Altershot, Dartmouth, 51-70.

13. Internal consistency of the religious belief measure: Cronbach Alpha's reliability coefficient $=0.70$.

14. Internal consistency of religious integration: Cronbach Alpha reliability coefficient $=0.73$.

15. Adorno T W (1957) 'The stars down to earth, the Los Angeles Times astrology column, a study in secondary superstition', Jahrbuch fuer Amerikastudien, Heidelberg, 2, 19-88, reprinted in R.Adorno, The stars down to earthand other essays on the irrational in culture, edited Stephen Crook (Routledge, London and New York, 1994).

16. See Durant, Evans, and Thomas (1989) op.cit.

17. Miller J D (1983) 'Scientific literacy: a conceptual and empirical review', Daedalus, 112, 3, 29-48; Miller J D (1991) 'The public understanding of science and technology in the United States', 1990, A report to the National Science Foundation, Dekalb, Illinois, February 1991.

18. We do recall from the Chicago meeting in 1992 that in the discussion an Indian theoretical physicist was quite irritated and outspoken about the tacit assumption in much of the discussion according to which science and astrology were incompatible. He made reference to the Indian context where Brahmanic knowledge traditions seem to have no problem of compatibility between modern science and astrology.

\section{Culture and Cosmos}


Martin Bauer and John Durant 71

19. Maitre J (1966) 'La consommation d'astrologie dans la societe contemporaine', Diogenes, 53, 92-109; Boy D \& G Michelat (1986) 'Croyance aux parasciences: dimensions sociales et culturelles', Revue Francaise de Sociologie, 27, 2, 175-204; Schmidtchen G (1957)

'Soziologisches ueber die Astrologie', Zeitschrift fuer Parapsychologie und Grenzgebiete der Psychologie, 1, 47-72.

20. Valadier P (1987) L'eglise en proces. Catholicism et societe modern, Paris, Flammarion; Pollack D (1990) 'Vom Tischrucken zur Psychodynamik. Formen ausserkirchlicher Religiositaet in Deutschland', Schweizerische Zeitschrift fuer Soziologie, 1, 107-134.

21. Adorno T W , Frenkel-Brunswik E, Levinson D J and Sanford R N (1950) The Authoritarian Personality, New York, Harper.

22. Aldrich J H and F D Nelson (1989) Linear probability, logit and probit models, New Bury Park, Sage. 